\title{
Secundum Atrial Septal Defect With Early Presentation of Eisenmenger Syndrome and Right-Heart Failure: A Rare Case Report and Literature Review
}

\author{
Jahanzeb Malik ${ }^{1}$, Umar Ikram ${ }^{1}$, Ahmed Kamal ${ }^{1}$, Ahsan Khalid Sr. ${ }^{1}$, Tayyaba Zahid ${ }^{1}$ \\ 1. Cardiology, Rawalpindi Institute of Cardiology, Rawalpindi, PAK
}

Corresponding author: Jahanzeb Malik, heartdoc86@gmail.com

\begin{abstract}
Eisenmenger syndrome, the most advanced form of pulmonary arterial hypertension (PAH), poses a considerable risk to the survival and quality of life of patients. It is more commonly seen in large intracardiac defects like ventricular septal defects (VSD) or patent ductus arteriosus (PDA), and rarely in atrial septal defects (ASD). Early diagnosis is the single most important step in the definitive management of the condition; otherwise, only conservative treatment can be offered. In this report, we present the case of a 20year-old female patient diagnosed with Eisenmenger syndrome secondary to a large secundum ASD. The
\end{abstract} patient responded well to medical treatment.

Received 06/22/2020 Review began 06/27/2020 Review ended 06/27/2020 Published 07/03/2020

() Copyright 2020 Malik et al. This is an open access article distributed under the terms of the Creative Commons Attribution License CC-BY 4.0., which permits unrestricted use, distribution, and reproduction in any medium, provided the original author and source are credited.
Categories: Cardiac/Thoracic/Vascular Surgery, Cardiology, Family/General Practice

Keywords: atrial septal defect, congenital heart disease, right to left shunt, eisenmenger, right heart cath, right heart failure

\section{Introduction}

Eisenmenger syndrome refers to the sequelae of untreated congenital heart defects (CHD) that lead to pulmonary hypertension [1-3]. Due to prolonged left-to-right shunt caused by a CHD, right-sided pulmonary pressures increase along with pulmonary vascular resistance, which causes shunt reversal leading to cyanosis [4]. CHDs like atrial septal defects (ASD) and ventricular septal defects (VSD) are characterized by high pressure in pulmonary vasculature leading to the sequela if untreated, but ASD usually presents in the fourth or fifth decade of life with Eisenmenger [5]. At this point, the defect is generally not operable. Eisenmenger syndrome itself has several grave complications like thromboembolism, infective endocarditis, heart failure, and arrhythmias [5]. It is a World Health Organization (WHO) risk class IV condition in pregnant females, and pregnancy is contraindicated according to the European Society of Cardiology guidelines [6]. Eisenmenger syndrome is more common with large VSD or patent ductus arteriosus (PDA) than with ASD [7]. Although its prevalence has decreased in the western countries [8], it remains a serious predicament in Pakistan where timely intervention still falls short. We present here a newly diagnosed case of a large ASD that was managed at our institute.

\section{Case Presentation}

A 20-year-old female, with a known history of heart murmur and non-compliant follow-up appointments, presented with dyspnea on exertion. She was admitted to the hospital with new-onset chest pain and shortness of breath. The pain was central and retrosternal, which was exacerbated when lying flat but improved while sitting. Her oxygen saturation was $83 \%$ and she was hypoxic. On physical exam, she had central cyanosis, jugular venous distention, parasternal heave, and a loud pan-systolic murmur. There was gross abdominal distension with ascites, and pedal edema with livedo reticularis. Her complete blood count revealed high hemoglobin of $18 \mathrm{~g} / \mathrm{dl}$, whereas liver function tests were mildly deranged with high alanine transaminase levels of $320 \mathrm{U} / \mathrm{L}$ and high gamma-glutamyltransferase levels of $60 \mathrm{U} / \mathrm{L}$ with borderline low albumin (2 g/dl). An electrocardiogram (ECG) showed a normal and regular heart rate with the right axis deviation as well as the right bundle branch block (Figure 1). The diagnosis was made on transthoracic echocardiography. It revealed a large ASD measuring $5.2 \mathrm{~cm}$, severe dilation of right atria and ventricle, and severe tricuspid regurgitation with a mean pulmonary artery pressure of $110 \mathrm{mmHg}$ (Figure 2; Video 1). 


\section{Cureus}

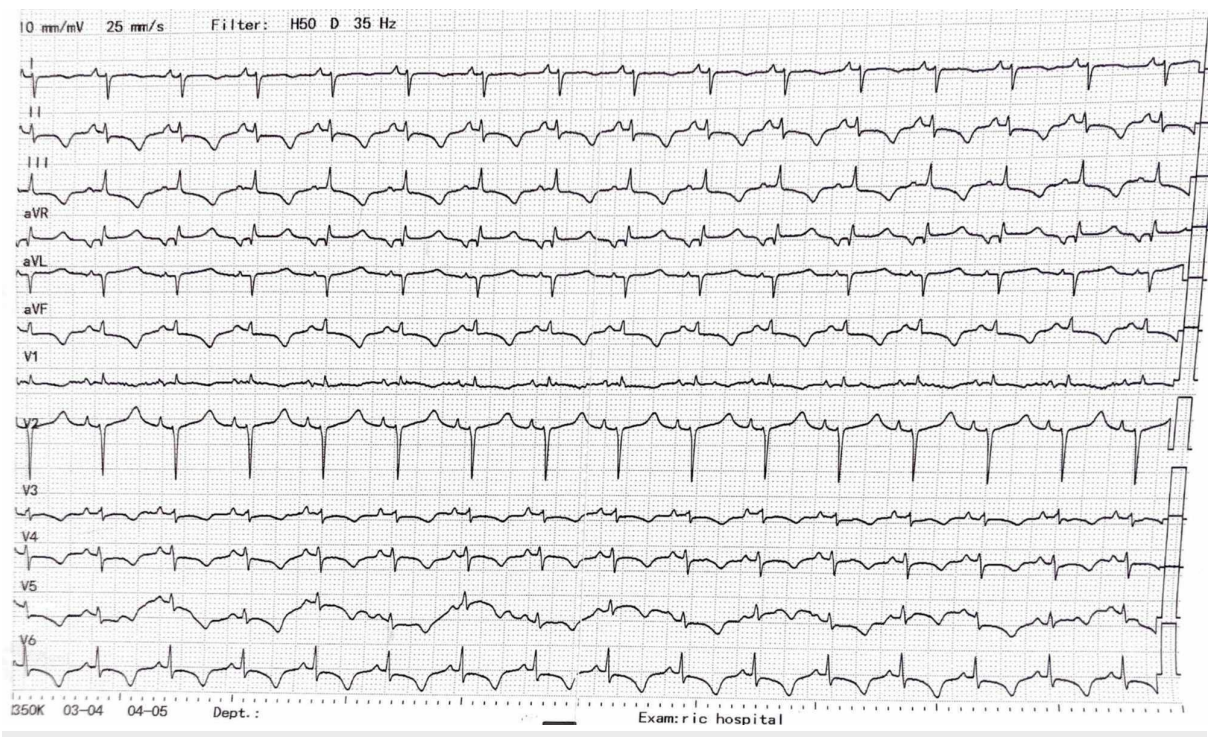

FIGURE 1: ECG showing right bundle branch block

ECG: electrocardiogram

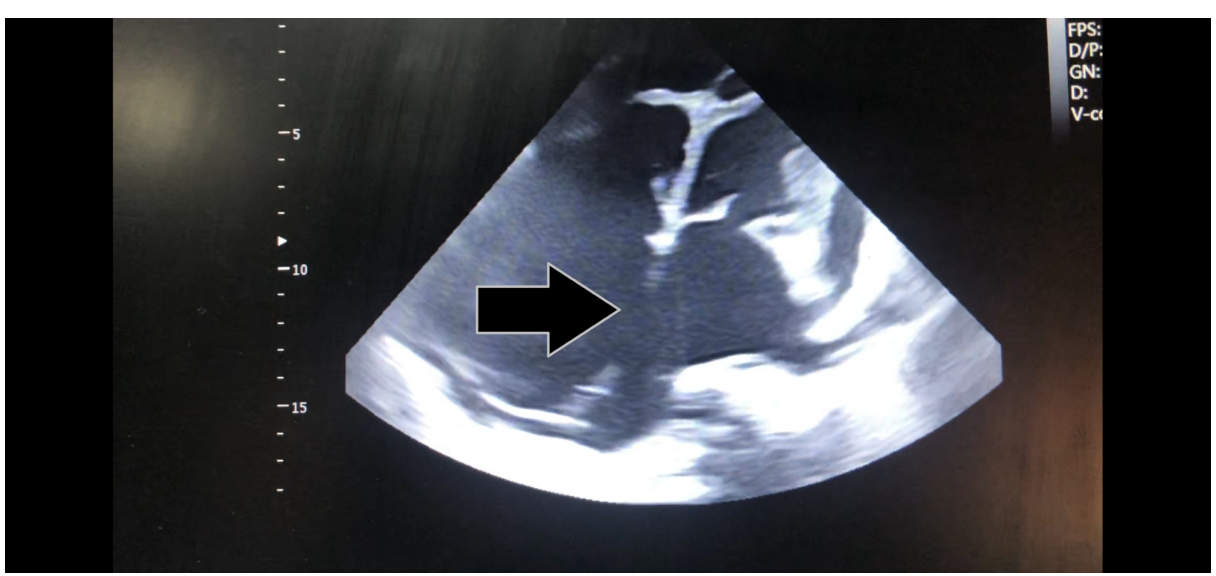

FIGURE 2: Large secundum atrial septal defect with a dilated right heart (black arrow)

There was a shunt reversal on the Doppler assessment of the defect. On right-heart catheterization, there was 10\% oxygen step-up from superior vena cava to right atrium indicating an ASD. Effective pulmonary blood flow to systemic blood flow (Qp/Qs) was 1, showing a bidirectional shunt and Eisenmenger physiology. Pulmonary artery pressure was increased $(80 \mathrm{mmHg})$ with high pulmonary vascular resistance $(9.2 \mathrm{Wood}$ units) and a mean wedge pressure of $3 \mathrm{mmHg}$. The patient's prognosis was predicted using a six-minute walk test. It was about 260 meters, less than $50 \%$ of the predicted distance. She was classified as New York Heart Association (NYHA) Class III and started on sildenafil tablet $20 \mathrm{mg}$ every eight hours and tablet bosentan $62.5 \mathrm{mg}$ every 12 hours for four weeks. Her acute congestive symptoms were controlled using digoxin 0.25 $\mathrm{mg}$ daily, spironolactone $50 \mathrm{mg}$ every 12 hours, and metoprolol $25 \mathrm{mg}$ every 12 hours. Her symptoms improved within three days of hospital admission and were followed up after 30 days. She no longer felt dyspnea on exertion and her NYHA Class improved to Class II. Her six-minute walk test doubled to 500 meters. 


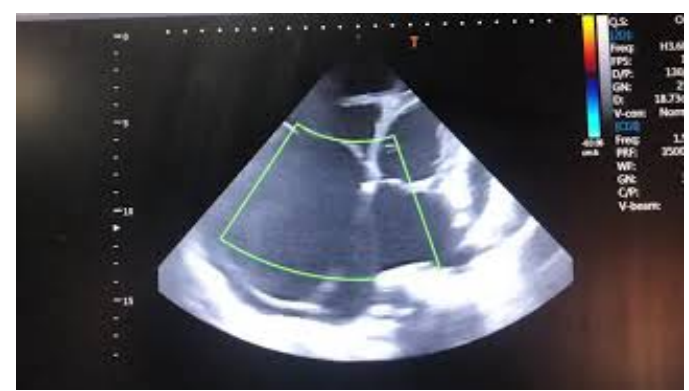

\section{VIDEO 1: Secundum atrial septal defect with two-dimensional and}

\section{Doppler assessment}

View video here: https://www.youtube.com/watch?v=Uel-o3fvht8

\section{Discussion}

After the bicuspid aortic valve, ASD is the most common adult CHD [9]. Approximately 70\% of the ASDs are of the secundum type [9]. Most patients with ASD become symptomatic in the third or fourth decade of life with pulmonary hypertension progressing to the Eisenmenger phenomenon; however, our patient was relatively young to have developed severe right-heart failure and shunt reversal. Although the late presentation of ASD can occur due to the asymptomatic nature of the disease, other factors may be responsible in third world countries like Pakistan. They include poverty, limited access to medical facilities, inadequate medical expertise and diagnostic, and belief in unorthodox medicine.

Based on published literature, Eisenmenger syndrome is a rare complication of ASD. It occurs in less than $5 \%$ of patients and its development requires genetic predisposition [10]. It is considered to be a multisystem, progressive disorder that may present as fatigue, central cyanosis, digital clubbing, syncope, hemoptysis, and heart failure as the disease progresses. In patients with ASD, it is prudent to suspect Eisenmenger when they are cyanosed at rest due to large unrestricted defects like in the case of our patient. The diagnostic workup should be thorough. History and physical exam are the cornerstones, with the help of cardiac imaging. Echocardiography is of paramount importance in assessing any CHD, as it is cheap, readily available, and non-invasive. Cardiac catheterization can be done to ascertain the degree of shunt and pulmonary vascular resistance but is rarely indicated in advanced cases where no invasive treatment is of benefit except palliation.

In advanced cases like ours, conservative treatment has been shown to be of some benefit [11]. Drugs like prostanoids, phosphodiesterase type- 5 inhibitors, and endothelin receptor antagonists are targeted at modifying the course of endothelin dysfunction. Studies have demonstrated an improvement in hemodynamics, exercise capacity, and quality of life in Eisenmenger syndrome [12]. There have been reports of Eisenmenger syndrome with ASDs as large as 2.5 by $3.5 \mathrm{~cm}$ with a known history of a murmur in a Nigerian male, and older males with the right bundle branch block as well as right ventricular hypertrophy [13]. Barnes et al. concluded that the mutations of bone morphogenetic protein receptor 2 (BMPR2) are responsible for $25 \%$ of idiopathic pulmonary arterial hypertension $(\mathrm{PAH})$ associated with a valvular defect [14]. The diagnosis is made by right-heart catheterization provided that the mean pulmonary arterial pressure at rest is at least $25 \mathrm{mmHg}$.

There are two approaches to management. As described by Nashat et al., safe closure is possible if the net left-to-right shunting is greater than 1.5 and pulmonary vascular resistance is less than 2.3 Wood units, which was not the case in our patient [15]. To our knowledge, elevated liver function tests have not been used as criteria for surgery. The conservative management focuses on monotherapy including endothelin receptor antagonists, phosphodiesterase- 5 inhibitors, and prostanoids. In a meta-analysis of eight studies, it was shown that bosentan and phosphodiesterase- 5 inhibitors improved exercise tolerance and reduced vascular remodeling in patients, at the cost of a few adverse effects [16].

It has been proposed that endothelial dysfunction plays a role in PAH, and hence bosentan is currently endorsed as the first-line treatment in patients with Eisenmenger syndrome in the WHO functional class IIIIV [17]. Endothelin-1 is a powerful vasoconstrictor seen in patients with PAH. This plays a key role in the pathogenesis of PAH by fibrosis and inflammation. These effects are produced by either endothelin A or endothelin B receptors on which endothelin receptor antagonists act, selectively targeting either single or both receptors [18]. In our patient, the functional improvement was seen after only a few weeks of treatment, which in turn endorses that theory.

\section{Conclusions}

Eisenmenger syndrome, a rare complication of ASD, is dictated by both the size of the defect and the absence of specific genes. The larger size is responsible for both right- and left-sided heart failure. In patients with a 
failure to satisfy the criteria, medical management has to be used to achieve optimal functional class and symptom relief.

\section{Additional Information \\ Disclosures}

Human subjects: Consent was obtained by all participants in this study. Conflicts of interest: In compliance with the ICMJE uniform disclosure form, all authors declare the following: Payment/services info: All authors have declared that no financial support was received from any organization for the submitted work. Financial relationships: All authors have declared that they have no financial relationships at present or within the previous three years with any organizations that might have an interest in the submitted work. Other relationships: All authors have declared that there are no other relationships or activities that could appear to have influenced the submitted work.

\section{Acknowledgements}

We thank Dr. Nismat Javed for her valuable suggestions and advice regarding the manuscript editing.

\section{References}

1. Kempny A, Hjortshøj CS, Gu H, et al.: Predictors of death in contemporary adult patients with Eisenmenger syndrome: a multicenter study. Circulation. 2017, 135:1432-1440. 10.1161/CIRCULATIONAHA.116.023033

2. Chaix MA, Gatzoulis MA, Diller GP, Khairy P, Oechslin EN: Eisenmenger syndrome: a multisystem disorderdo not destabilize the balanced but fragile physiology. Can J Cardiol. 2019, 35:1664-1674. 10.1016/j.cjca.2019.10.002

3. Hjortshøj CS, Kempny A, Jensen AS, et al.: Past and current cause-specific mortality in Eisenmenger syndrome. Eur Heart J. 2017, 38:2060-2067. 10.1093/eurheartj/ehx201

4. Hascoët S, Baruteau AE, Humbert M, et al.: Long-term outcomes of pulmonary arterial hypertension under specific drug therapy in Eisenmenger syndrome. J Heart Lung Transplant. 2017, 36:386-398. 10.1016/j.healun.2016.10.006

5. Yuan SM: Eisenmenger syndrome in pregnancy. Braz J Cardiovasc Surg. 2016, 31:325-329. 10.5935/16789741.20160062

6. Suwanrath C, Thongphanang P, Pinjaroen S, Suwanugsorn S: Validation of modified World Health Organization classification for pregnant women with heart disease in a tertiary care center in southern Thailand. Int J Womens Health. 2018, 10:47-53. 10.2147/IJWH.S150767

7. Restivo A, di Gioia CR, Anderson RH, Carletti R, Gallo P: The Eisenmenger malformation: a morphologic study. Cardiol Young. 2016, 26:269-279. 10.1017/S1047951115000104

8. Kempny A, Dimopoulos K, Gatzoulis MA: Declining incidence and prevalence of Eisenmenger syndrome in the developed world: a triumph of modern medicine. Heart. 2017, 103:1313-1314. 10.1136/heartjnl-2017311396

9. Zwijnenburg RD, Baggen VJM, Geenen LW, Voigt KR, Roos-Hesselink JW, van den Bosch AE: The prevalence of pulmonary arterial hypertension before and after atrial septal defect closure at adult age: a systematic review. Am Heart J. 2018, 201:63-71. 10.1016/j.ahj.2018.03.020

10. Forlemu AN, Ajmal M, Saririan M: Atrial septal defect with Eisenmenger syndrome: a rare presentation . Case Rep Cardiol. 2020, 2020:1-4. 10.1155/2020/8681761

11. Hascoet S, Fournier E, Jaïs X, et al.: Outcome of adults with Eisenmenger syndrome treated with drugs specific to pulmonary arterial hypertension: a French multicentre study. Arch Cardiovasc Dis. 2017, 110:303-316. 10.1016/j.acvd.2017.01.006

12. Diller GP, Körten MA, Bauer UM, et al.: Current therapy and outcome of Eisenmenger syndrome: data of the German National Register for congenital heart defects. Eur Heart J. 2016, 37:1449-1455. 10.1093/eurheartj/ehv743

13. Gatzoulis MA, Beghetti M, Galiè N, et al.: Longer-term bosentan therapy improves functional capacity in Eisenmenger syndrome: results of the BREATHE-5 open-label extension study. Int J Cardiol. 2008, 127:2732. 10.1016/j.ijcard.2007.04.078

14. Barnes JW, Kucera ET, Tian L, et al.: Bone morphogenic protein type 2 receptor mutation-independent mechanisms of disrupted bone morphogenetic protein signaling in idiopathic pulmonary arterial hypertension. Am J Respir Cell Mol Biol. 2016, 55:564-575. 10.1165/rcmb.2015-0402OC

15. Nashat H, Montanaro C, Li W, et al.: Atrial septal defects and pulmonary arterial hypertension. J Thorac Dis. 2018, 10:S2953-S2965. 10.21037/jtd.2018.08.92

16. Dang ZC, Tang B, Li B, Liu S, Ge RL, Li ZQ, Lu DX: A meta-analysis of the safety and efficacy of bosentan therapy combined with prostacyclin analogues or phosphodiesterase type-5 inhibitors for pulmonary arterial hypertension. Exp Ther Med. 2019, 18:4740-4746. 10.3892/etm.2019.8142

17. Dimopoulos S, Tzanis G, Manetos C, et al.: Peripheral muscle microcirculatory alterations in patients with pulmonary arterial hypertension: a pilot study. Respir Care. 2013, 58:2134-2141. 10.4187/respcare.02113

18. Radke RM, Diller GP, Baumgartner H: The challenge of managing pulmonary arterial hypertension in adults with congenital heart disease. Expert Rev Cardiovasc Ther. 2013, 11:919-931.

$10.1586 / 14779072.2013 .811966$ 